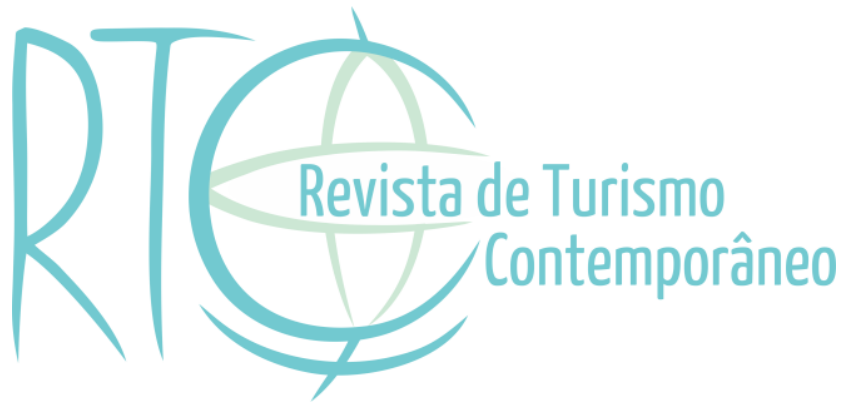

\title{
Do ensino presencial ao remoto: experiências dos docentes do bacharelado em Turismo durante a pandemia da Covid-19
}

From face-to-face to remote teaching: experiences of teachers of the bachelor's degree in Tourism during the Covid-19 pandemic

\section{Marina Hastenreiter Silva}

Professora substituta do curso de hotelaria na Universidade Federal Rural do Rio de Janeiro

- UFRRJ, Seropédica/RJ, Brasil

E-mail: marinahs@id.uff.br

Roberto Soares da Cruz Hastenreiter

Professor efetivo do Instituto Federal de Educação, Ciência e Tecnologia do Rio de Janeiro IFRJ, Rio de Janeiro/RJ, Brasil

E-mail: roberto.cruz@ifrj.edu.br

\section{Mayra Laborda Santos}

Mestra em Turismo pela Universidade Federal Fluminense - UFF, Niterói/RJ, Brasil E-mail: mayra_laborda@id.uff.br

Ivan Conceição Martins da Silva

Mestre em Turismo pela Universidade Federal Fluminense - UFF, Niterói/RJ, Brasil E-mail: ivanmartins@id.uff.br

Artigo recebido em: 09-12-2020

Artigo aprovado em: 21-01-2021 


\section{RESUMO}

A imposição de isolamento social decorrente da pandemia da Covid-19 desencadeou a suspensão das aulas presenciais em toda rede pública e privada de ensino no Brasil. Com isso, docentes de instituições privadas de cursos superiores presenciais de turismo se depararam com a realidade de lecionar longe da convencional sala de aula, tendo que transpor o planejamento pedagógico pautado no ensino presencial para o ensino remoto. Perante essa conjuntura, o objetivo geral desta pesquisa foi investigar as experiências desses docentes devido à implementação do ensino remoto. Quanto aos procedimentos metodológicos, adotou-se a abordagem qualitativa, tendo como instrumento de coleta de dados entrevistas semiestruturadas online com docentes de cursos presenciais de bacharelado em turismo de instituições privadas no estado do Rio de Janeiro, no período de 21 a 28 de maio de 2020. A sistematização e análise de dados ocorreu baseada na pesquisa de Estrada-Villa (2014), concomitantemente ao uso dos pressupostos de análise categorial-temática de Bardin (2011). Como resultados, identificou-se oito categorias: (1) atitude e interesse; (2) características dos estudantes; (3) política da Instituição de Ensino Superior; (4) ferramentas e recursos tecnológicos; (5) treinamento; (6) capacitação docente; (7) ambiente de trabalho e trabalho de reprodução social; (8) condições físicas e psicológicas. Logo, o ensino remoto não apenas expôs o problema da desigualdade ao acesso à tecnologia digital, mas também vários outros problemas que atingem tanto docentes quanto discentes: ambiência para estudos; saúde mental-psicológica; e falta de políticas públicas direcionadas à primeira infância para auxiliar mães e pais docentes.

Palavras-chave: Covid-19. Trabalho Docente. Ensino Remoto. Turismo.

\section{ABSTRACT}

The imposition of social isolation resulting from the Covid-19 pandemic triggered the suspension of face-to-face classes in all public and private schools in Brazil. As a result, professors from private institutions of on-campus higher education courses faced the reality of teaching away from the conventional classroom, having to transpose the pedagogical planning based on classroom teaching to remote teaching. In view of this situation, the general objective of this research was to investigate the experiences of these teachers due to the implementation of remote education. As for the methodological procedures, a qualitative approach was adopted, using semi-structured online interviews as a data collection instrument with professors from on-campus bachelor's degrees in tourism from private institutions in the state of Rio de Janeiro, from May 21 to 28, 2020. The systematization and analysis of data occurred based on the research by Estrada-Villa (2014), concomitantly with the use of the assumptions of categoricalthematic analysis of Bardin (2011). As a result, eight categories were identified: (1) attitude and interest; (2) student characteristics; (3) Higher Education Institution policy; (4) technological tools and resources; (5) training; (6) teacher training; (7) work environment and social reproduction work; (8) physical and psychological conditions. Therefore, remote education not only exposed the problem of inequality in access to digital technology, but also several other problems that affect both teachers and students: ambience for studies; mental-psychological health; and lack of public policies aimed at early childhood to assist teaching mothers and fathers.

Keywords: Covid-19. Teaching Work. Remote Teaching. Tourism. 


\section{INTRODUÇÃO}

No final de dezembro de 2019, registrou-se na cidade de Wuhan, capital da província de Hubei (China), casos de pessoas infectadas por um novo coronavírus, identificado como SARS-CoV-2 (Li et al., 2020; Qun et al., 2020). Esse vírus causa a doença infecciosa Covid19, caracterizada por alta transmissibilidade e evolução para casos graves, principalmente na população idosa e com fatores de risco. Em Wuhan, assim que as autoridades detectaram o aumento expressivo de casos, foram adotadas medidas de prevenção e controle para conter o avanço do vírus, como: restrição de mobilidade, quarentena, identificação dos casos, proibição de eventos ou reuniões que produzissem aglomerações.

A partir do acompanhamento da evolução da epidemia na China e o surgimento de novos casos em outros países e continentes, a Organização Mundial de Saúde (OMS) decretou, em 11 de março de 2020, situação de pandemia. Nesse momento, existiam aproximadamente 118.000 casos em 114 países e 4.291 mortes (Organização Mundial de Saúde - OMS, 2020).

No Brasil, o quadro de evolução da doença se deu a partir do primeiro caso detectado no dia 26 de fevereiro de 2020 na cidade de São Paulo, de um paciente que havia viajado para a Itália (Brasil, 2020a). Já o primeiro caso no estado do Rio de Janeiro foi identificado em 05 de março de 2020, de uma paciente também com histórico de viagem à Itália (Empresa Brasil de Comunicação - EBC, 2020).

Em função do avanço da transmissibilidade da Covid-19, o governador do estado do Rio de Janeiro, por meio do Decreto $\mathrm{n}^{\circ} 47246$ de 12 de março de 2020, estabeleceu a suspensão de aulas na rede pública e privada, inclusive nas unidades de ensino superior a fim de reduzir o contágio (Imprensa Oficial do Estado do Rio de Janeiro - IOERJ, 2020). Na ausência de medicamento, vacina e leitos para atender a população precisando de hospitalização, a medida de distanciamento social se faz necessária para reduzir o ritmo de contágio.

Em um curto período, os docentes que atuavam em cursos presenciais de bacharelado em turismo de instituições de ensino superior (IES) privadas no estado do Rio de Janeiro se depararam com a obrigatoriedade do uso de plataformas digitais, gravação de videoaula, readaptação do plano de aula, avaliações virtuais, criação de materiais pedagógicos para disponibilizar nas plataformas, entre outros. Ademais, essa adequação se deu no período de obrigatoriedade da quarentena e de isolamento social, ou seja, nas residências dos docentes. Destaca-se que alguns tiveram que adequar seus espaços privados para poderem realizar as aulas online, compartilhando estas com atividades domésticas, e por vezes tendo que negociar com os demais residentes. 
Os docentes das universidades públicas enfrentaram processos similares, porém meses após o início da quarentena obrigatória. As universidades públicas contaram com mais tempo de suspensão das atividades acadêmicas nos cursos de graduação e, consequentemente, tiveram um pouco mais de tempo para decidir e preparar a retomada de aulas de forma remota.

O ensino superior em turismo no Brasil teve como base o Parecer CFE $n^{\circ} 35 / 71$, de 28 de janeiro de 1971 (Brasil, 2020b). Segundo o estudo de Silveira, Medaglia e Gândara (2012), houve grande oferta de cursos de Turismo no Brasil na década de 1990, devido ao incentivo de políticas nesse setor. Além disso, os referidos autores destacam que esse crescimento teve seu ápice em 2007, mas depois começou a declinar, cenário que perdura até os dias atuais (Silveira, Medaglia \& Gândara, 2012).

Atualmente, no estado do Rio de Janeiro, há cinco instituições públicas e sete privadas que oferecem cursos de graduação presencial de bacharelado em turismo e de tecnologia em Gestão em Turismo. Desse total, sete se concentram na cidade do Rio de Janeiro. O quadro 1 apresenta essas instituições, seus respectivos cursos e localidade.

Quadro 1 - Instituições de ensino superior privadas e públicas com graduação presencial em bacharelado em Turismo e Gestão em Turismo no Estado do Rio de Janeiro

\begin{tabular}{|c|c|c|c|c|}
\hline \multicolumn{2}{|r|}{ Instituições de Ensino Superior } & \multirow{2}{*}{$\begin{array}{c}\begin{array}{c}\text { Curso de } \\
\text { Bacharelado }\end{array} \\
\mathrm{X}\end{array}$} & \multirow{2}{*}{$\begin{array}{c}\text { Curso Superior de Tecnologia } \\
\text { em Gestão de Turismo } \\
\text { (Tecnólogo) }\end{array}$} & \multirow{2}{*}{$\begin{array}{c}\text { Municípios } \\
\begin{array}{c}\text { Rio de Janeiro, } \\
\text { Niterói }\end{array}\end{array}$} \\
\hline 1 & $\begin{array}{l}\text { Universidade Estácio de Sá } \\
\text { (UNESA) }\end{array}$ & & & \\
\hline 2 & $\begin{array}{c}\text { Universidade Veiga de Almeida } \\
\text { (UVA) }\end{array}$ & $\mathrm{X}$ & 0 & Rio de Janeiro \\
\hline 3 & $\begin{array}{l}\text { Centro Universitário Gama e } \\
\text { Souza (UNIGAMA) }\end{array}$ & $\mathrm{X}$ & 0 & Rio de Janeiro \\
\hline 4 & $\begin{array}{l}\text { Centro Universitário } \\
\text { Anhanguera de Niterói }\end{array}$ & $\mathrm{X}$ & 0 & Niterói \\
\hline 5 & Centro Universitário São José & $\mathrm{X}$ & 0 & Rio de Janeiro \\
\hline 6 & $\begin{array}{l}\text { Faculdade Lusófona do Rio de } \\
\text { Janeiro }\end{array}$ & $\mathrm{X}$ & 0 & São Gonçalo \\
\hline 7 & $\begin{array}{l}\text { Faculdade Machado de Assis } \\
\text { (FAMA) }\end{array}$ & $X$ & 0 & Rio de Janeiro \\
\hline 8 & $\begin{array}{l}\text { Universidade Federal } \\
\text { Fluminense (UFF) }\end{array}$ & $\mathrm{X}$ & 0 & Niterói \\
\hline 9 & $\begin{array}{l}\text { Universidade Federal Rural do } \\
\text { Rio de Janeiro (UFRRJ) }\end{array}$ & $\mathrm{X}$ & 0 & Nova Iguaçu \\
\hline
\end{tabular}




\begin{tabular}{|c|c|c|c|c|}
\hline 10 & $\begin{array}{c}\text { Universidade Federal do Estado } \\
\text { do Rio de Janeiro (UNIRIO) }\end{array}$ & $\mathrm{X}$ & 0 & Rio de Janeiro \\
\hline 11 & $\begin{array}{c}\text { Universidade do Estado do Rio } \\
\text { de Janeiro (UERJ) }\end{array}$ & $\mathrm{X}$ & 0 & Rio de Janeiro \\
\hline 12 & $\begin{array}{c}\text { Centro Federal de Educação } \\
\text { Celso Suckow da Fonseca } \\
\text { (CEFET) }\end{array}$ & $\mathrm{X}$ & $\mathrm{X}$ & $\begin{array}{c}\text { Friburgo, } \\
\text { Petrópolis }\end{array}$ \\
\hline
\end{tabular}

Fonte: Elaborado pelos autores baseado no Ministério da Educação - MEC (Brasil, 2020c).

A partir do Quadro 1, observou-se que há oferta de cursos superiores de turismo em instituições públicas e privadas que contribuem para formação de profissionais para atuar tanto no mercado de trabalho quanto na academia. Assim, torna-se relevante a compreensão das vivências desses docentes durante o atual momento histórico.

Portanto, o presente trabalho teve como objetivo geral investigar as experiências dos docentes de cursos presenciais de bacharelado em turismo de instituições privadas, no estado do Rio de Janeiro, devido à mudança do ensino presencial para o ensino remoto em decorrência da pandemia de Covid-19.

A pesquisa teve como recorte temporal os meses de março, abril e maio, visando levantar as experiências dos docentes afetados imediatamente pelo processo conjunto de quarentena obrigatória e implantação sem preparação prévia do ensino remoto. A abordagem exclusiva de docentes de IES privadas se deu, portanto, exatamente por as IES públicas não terem retornado suas atividades ainda no período analisado.

Em relação aos procedimentos metodológicos, adotou-se a abordagem qualitativa, tendo como instrumento de coleta de dados entrevistas semiestruturadas online com docentes de cursos presenciais de bacharelado em turismo de instituições privadas de ensino superior no estado do Rio de Janeiro, no período de 21 a 28 de maio de 2020. Destaca-se que nesse momento a quarentena era obrigatória conforme Decreto Estadual nº 47068 de 11 de maio de 2020. A sistematização e análise de dados ocorreu a partir da Análise de Conteúdo categorial-temática (Bardin, 2011), e as categorias foram construídas de forma indutiva a partir dos depoimentos verbais dos entrevistados.

Por fim, pretendeu-se com esse estudo contribuir com as investigações e reflexões sobre a educação superior na área de turismo durante a pandemia da Covid-19 e como os docentes de cursos superiores presenciais de turismo lidaram com esse contexto frente à abrupta modificação do ensino presencial para o ensino remoto. 


\section{O ENSINO NO CONTEXTO DO USO DE TECNOLOGIAS DIGITAIS}

O uso de novas tecnologias na educação tem sido discutido há mais de duas décadas (Apple, 1986; Oliveira et al., 1993; Tosta \& Oliveira, 2000; Ellis \& Goodyear, 2016). Contudo, a partir do início do século XXI, com o avanço das novas tecnologias e do aumento da população com acesso aos meios digitais, houve a ampliação dessas discussões. Duvivier (2019) aponta avanços no processo de acesso aos conteúdos digitais a partir dos anos 2000: iPod (lançado em 2001); YouTube (criado em 2005), leitores de livros eletrônicos, como o Kindle da Amazon (2008); e acesso à internet por banda larga móvel como 3G (lançado em 2003).

Segundo Costa, Duqueviz e Pedroza (2015), o termo Tecnologias da Informação e Comunicação (TIC) é o mais utilizado para se referir aos dispositivos eletrônicos e tecnológicos, como computador, internet, tablet e smartphone. Além disso, as TICs também abrangem as tecnologias mais antigas como a televisão, vídeo cassete, rádio, jornal, etc. Por isso, na sociedade contemporânea, pesquisadores têm utilizado o termo Tecnologias Digitais da Informação e Comunicação (TDIC) (Baranauskas \& Valente, 2013) ou novas tecnologias (Kenski, 1998, 2012) para se referir às tecnologias digitais.

Kenski (2012) conceitua as novas tecnologias de informação e comunicação (NTICs) a partir da linguagem digital. Portanto, assim como no estudo de Costa, Duqueviz e Pedroza (2015), os termos TDIC, novas tecnologias e tecnologias digitais foram considerados de forma indistinta para referir-se a computador, tablet, celular, smartphone e qualquer outro dispositivo eletrônico digital e tecnológico que permita a navegação na internet.

Ainda que em um contexto mundial, que leva em consideração países onde os avanços tecnológicos chegam com certa antecedência se comparados com o Brasil, esses avanços deram aos usuários diversas formas de acessar conteúdos de informação e de construir conhecimento. O referido autor destaca que em 1995 menos de $1 \%$ da população mundial tinha acesso à internet e que, em 2017, já eram 40\% com acesso. Atualmente, mesmo no Brasil, os avanços na internet sem fio e nos dispositivos portáteis (smartphones) permitem a alguns estudantes flexibilidade temporal e espacial.

No contexto do ensino e aprendizagem, e particularmente no ensino superior, as mudanças provenientes de novas ferramentas digitais e tecnológicas podem impactar e trazer modificações em diversas dimensões (inter-relacionadas), das quais destaca-se: pedagógica; docente; discente; institucional (Kenski, 2012). 
Os impactos relacionados à pedagogia se referem às novas formas de descobrir e construir conhecimento que seja significativo para os estudantes. As questões relacionadas aos docentes envolvem formação inicial e continuada, acessibilidade e condições materiais e psicológicas dos professores. Estes dois últimos são pertinentes também ao segmento discente. E a acessibilidade pode ser vista como uma característica que inclui também as instituições. De alguma forma, essas dimensões são contempladas no trabalho de Duvivier (2019), no qual o autor destaca que o aumento da acessibilidade dos dispositivos móveis, a ampliação da rede de banda larga e o maior acesso a redes Wi-Fi (gratuitas) são fatores que contribuem para a perspectiva do uso desses dispositivos na educação superior.

Esse conjunto de fatores resulta em impactos pedagógicos, ou seja, novas formas de interagir com conteúdos educacionais que trazem consequências tanto no planejamento dos cursos quanto na formação dos docentes, nas formas de avaliação, nas ações didáticas e até em aspectos cognitivos. Além disso, há impactos ligados à infraestrutura dos campi universitários, pois, devido às novas tecnologias e, em especial, ao uso de dispositivos móveis, o acesso facilitado à internet faz com que não somente espaços como a biblioteca e salas de estudos sejam ocupados com fins acadêmicos, mas, também, cafeterias, praças de alimentação, dentre outros ambientes.

Concernente aos impactos relacionados aos estudantes, Duvivier (2019) destaca que a tecnologia permite aos discentes a adaptação de suas atividades acadêmicas conforme suas rotinas pessoais (compromissos de trabalho, familiar, saúde, etc.), uma vez que parte de suas atividades acadêmicas podem ser realizadas fora do campus universitário.

Segundo a Organização das Nações Unidas para Educação, Ciência e Cultura (UNESCO) há definições sobre o aprendizado móvel, que inclui o uso de ferramentas de acesso a conteúdos digitais a partir de dispositivos móveis (smartphones, tablets, etc.). Destaca-se, de acordo com Unesco (2012), que:

\footnotetext{
Uma definição popular de aprendizado móvel é a educação que envolve o uso de dispositivos móveis para permitir o aprendizado a qualquer momento e em qualquer lugar. Embora essa definição capte grande parte da essência do aprendizado móvel, ela requer dois esclarecimentos importantes. As discussões sobre a aprendizagem móvel devem: 1) concentrar-se mais na mobilidade e em seus recursos exclusivos do que na tecnologia em si; e 2) incluem [sic] perguntas sobre como os dispositivos móveis podem apoiar não apenas a aprendizagem, mas também objetivos educacionais amplos, como administração educacional eficaz e gerenciamento de informações (Organização das Nações Unidas para Educação, Ciência e Cultura UNESCO, 2012, p. 10).
} 
Certamente as ferramentas tecnológicas abordadas na perspectiva da presente pesquisa não se limitam aos dispositivos móveis. Contudo, destaca-se que para o contexto atual, e com profunda pertinência aos objetivos dessa pesquisa, o uso de tais dispositivos de acesso digital tem ampla relevância.

Estrada-Villa (2014) apresentou um conjunto de elementos que favorecem e desfavorecem a aprendizagem baseada no uso de novas tecnologias na educação. A construção dos referidos grupos de categorias foi resultado da síntese de sua pesquisa com uma amostra de 176 docentes que atuam no ensino superior em universidades colombianas. A autora lista como aspectos favoráveis: (1) fator atitude e interesse; (2) fator características do estudante; (3) fator de política da Instituição de Ensino Superior (IES); (4) fator de infraestrutura; (5) fator de campo de estudo; (6) fator de treinamento; (7) fator de conhecimento e habilidades; e (8) fator de gerenciamento. Por outro lado, são listados como aspectos desfavoráveis, no referido trabalho: (1) fator atitude e desinteresse; (2) fator desconhecimento; (3) fator falta de gestão administrativa e apoio institucional; (4) fator ausência de diretrizes; (5) fator falta de capacitação; (6) fator falta de infraestrutura.

Tendo em vista as singularidades referentes ao contexto sócio-histórico e político de uma crise sanitária de escala mundial no qual a presente pesquisa se insere, buscou-se algumas aproximações, fundamentalmente, com pesquisas que apontam aspectos relacionados com as práticas docentes na relação do ensino e do uso de tecnologias digitais, a exemplo da pesquisa de Estrada-Villa (2014).

\subsection{Ensino remoto em tempos da Covid-19: perspectivas e discussões}

Em face da imposição de isolamento social, e consequentemente da suspensão das aulas presenciais em toda rede pública e privada de ensino no Brasil, os docentes foram colocados em uma situação inédita na qual tiveram que transpor, 'da noite para o dia', o planejamento pedagógico pautado no ensino presencial para o ensino remoto. Tiveram que se adaptar à nova rotina pautada no uso de plataformas tecnológicas digitais em rede para preparar e lecionar suas aulas, reunir os discentes virtualmente e dar continuidade ao conteúdo curricular.

Durante esse período excepcional, observou-se que as instituições de ensino com cursos presenciais adotaram diferentes termos para caracterizar a modalidade de ensino que estavam realizando. Desse modo, percebeu-se certa confusão conceitual, na qual os termos educação a distância (EAD), educação remota e educação online são utilizados como sinônimos. Em razão disso, torna-se importante entender as distinções entre cada uma. 
Historicamente, considera-se como EAD as formas de educação formal pautadas em um pensamento curricular, com intencionalidade pedagógica e práticas educacionais que usam tecnologias para criar ambiências formativas para pessoas que estão geograficamente dispersas (Moore \& Kearsley, 2008; Preti, 2005; Saraiva, 1996).

Sendo assim, o desenvolvimento da EAD se divide em dois momentos, antes e depois do advento da internet. No primeiro caso, o modelo EAD era constituído por várias mídias massivas e a mediação era feita por meio de materiais impressos, audiovisualidades desconectadas, e a combinação de ambas (Saraiva, 1996). Desta maneira, o estudante recebia o material institucional impresso com conteúdo e situações de aprendizagem para estudar e aprender. Assim, por muito tempo, as pessoas aprenderam por meio da EAD utilizando mídias massivas e autoestudo.

O segundo momento foi influenciado pela mudança no paradigma comunicacional das mídias. Com a advento da internet houve a liberação do polo da emissão fazendo com que pessoas que estavam dispersas geograficamente pudessem se 'encontrar' porque foi possível permitir aos estudantes acesso à sala de aula virtual, à sociabilização 'virtual' e trocas de informações e até a criação de sentimentos de pertencimento e comunidade (Santos, 2019). Por isso, a internet mudou a forma comunicacional de atuar com a educação a distância.

Com base nisso, para que uma modalidade de ensino seja denominada EAD é preciso planejamento, metodologia e teoria para desenvolvê-la e aplicá-la. Considera-se como elementos pedagógicos que compõem a EAD: (a) organização curricular prévia, (b) elaboração de materiais didáticos adequados aos estudantes, (c) mediação proporcionada pelas mídias impressas ou digitais e (d) plataforma virtual.

Já a modalidade de educação online não é considerada uma evolução da EAD, porque a comunicação via internet gerou um outro paradigma comunicacional e outra forma de se relacionar em nosso tempo, conhecida como cibercultura (Santos, 2019). Portanto, entende-se como educação online qualquer situação de aprendizagem, qualquer ambiência formativa mediada por tecnologias digitais em rede, sem necessariamente estar à distância. Nesse sentido, mesmo em cursos presenciais há a possibilidade de desenvolver educação online em uma sala de aula presencial ou atividades mediadas via internet, como os ambientes virtuais de aprendizagem (AVA). Por isso, entende-se que a educação online é um fenômeno da cibercultura, mediada pelo digital em rede e também requer pensamento curricular (Santos, 2019).

No entanto, o ensino remoto se caracteriza por não ter planejamento prévio e ser implantado de forma improvisada pelas instituições educacionais a fim de dar continuidade às 
aulas e às demais demandas educacionais, sobretudo, o encontro (virtual) entre docentes e discentes por meio de plataformas e interfaces de webconferência.

Pode apreender-se que ensino remoto se diferencia da EAD e da educação online em função da organização geral do processo de ensino-aprendizagem. Como um modelo de adaptação situacional, o ensino remoto não conta com um planejamento prévio estruturante de currículo, materiais e método pedagógico - é, portanto, uma transposição de um planejamento baseado em atividades presenciais para atividades remotas. Esse processo carrega, portanto, dificuldades e entraves para um desenvolvimento pleno da atividade docente, visto que não pode contemplar exatamente o que se pretendia com as atividades presenciais nem plenamente a experiência de educação a distância ou online.

Em meio a tantos desafios e instigações que a pandemia da Covid-19 provoca na educação, a cultura digital ou cibercultura ainda é uma grande adversidade para o ensino no Brasil, uma vez que é preciso o conhecimento de como utilizá-la, sobretudo de forma dialética e em prol da educação. Além disso, boa parte da população brasileira não tem acesso às tecnologias digitais em rede, ou se a tem, por vezes não é adequada às demandas das atividades remotas.

\section{TECNOLOGIAS E A FORMAÇÃO DOCENTE NOS CURSOS SUPERIORES DE}

\section{TURISMO}

O turismo está se deparando, como em nenhum outro período histórico, com um cenário complexo e imprevisível. Consequentemente, o sistema formal de ensino voltado para a formação de turismólogos tende a pensar as novas demandas trazidas pela Covid-19. Santos (2007) defende como qualificações do profissional de turismo: conhecimento, flexibilidade, adaptabilidade, competência, intervenção e eficácia. No contexto pandêmico, as referidas qualificações ganham ressignificação e amplitude em sua importância.

Ademais, o turismo é conhecido como um setor amplamente dinâmico, transformado constantemente por causas como avanços nas tecnologias de comunicação e transportes, sazonalidade e uma alta sensibilidade a mudanças nos contextos sociais, políticos e ambientais dos destinos. Mesmo assim, a pandemia da Covid-19 demonstrou que tais volatilidades podem ser ainda mais acentuadas. Nesse sentido, as competências referidas por Santos (2007) assumem novos contornos. Os profissionais de turismo precisam, mais do que nunca, estar preparados para reagir a mudanças bruscas na realidade social. 
Diante disso, os docentes da área do turismo precisam se preparar pedagogicamente para que a formação aconteça. Sabe-se que a junção do conhecimento tácito e teórico na formação desses docentes é algo discutido e defendido há algum tempo (Ansarah, 1995; Santos, 2007; Trigo, 1998, 2000). No entanto, por ora, esses dois pilares estão em construção em relação aos temas e aos novos paradigmas que a Covid-19 trouxe para o ensino superior na área de turismo.

O estudo de Catramby e Costa (2005), sobre a educação em turismo nas Instituições de Ensino Superior (IES) no estado do Rio de Janeiro, identificou que a capacitação docente é um dos fatores que influencia na qualidade da formação profissional. Como visto na subseção anterior, não há planejamento prévio educacional no ensino remoto. Logo, ante a prorrogação das suspensões das aulas presenciais, o pilar pedagógico no processo de formação de turismólogos também pode ter resultados negativos. Além disso, outro ponto a ser destacado é como lecionar, em tempos de pandemia, as disciplinas com conteúdo teórico-prático que compreendem visitas técnicas, inventário turístico, laboratórios de aprendizagem e estágio?

Se antes da pandemia já se discutia as transformações no setor da educação em função do avanço das TICs (Trigo, 2000), com a Covid-19 a educação tende a utilizar cada vez mais as diversas ferramentas digitais e tecnológicas. No entanto, isso pode não significar melhor interatividade durante as aulas e nem que o ensino-aprendizagem ocorra de forma satisfatória.

Por isso, torna-se importante investir no processo de formação dos docentes quanto ao uso de tecnologias digitais, tendo em vista a combinação de diferentes modalidades formativas para que se promova justiça cognitiva, ambiências formativas e sociabilidade no espaço da cibercultura (Santos, 2019). Por fim, acredita-se que a padronização de técnicas nos meios virtuais pode afetar a essência da pedagogia.

\section{METODOLOGIA}

A presente pesquisa caracterizou-se como exploratória-descritiva, com abordagem qualitativa e o método indutivo. Entende-se exploratória por ter a perspectiva de colaborar com as reflexões sobre a temática educacional no ensino superior em tempos de pandemia, contribuindo para uma melhor compreensão das possíveis estratégias a serem pensadas e utilizadas no problema em questão (Gil, 2002). Além disso, o presente trabalho também tem caráter descritivo porque, a partir do processo analítico da abordagem exploratória, foram descritas as reflexões, vivências e experiências dos docentes durante o período do ensino remoto.

Em função da obrigatoriedade de isolamento social derivada da pandemia da Covid-19, utilizou-se como instrumento de coleta de dados entrevistas virtuais com perguntas 
semiestruturadas realizadas por meio da plataforma Google Meet. No total, foram entrevistados cinco docentes, de duas diferentes instituições privadas de ensino superior do estado do Rio de Janeiro, no período de 21 de maio de 2020 a 28 de maio 2020. Essa amostra se caracterizou como não-probabilística por conveniência (Cochran, 1965). No Quadro 2 são apresentados dados referentes à amostra.

Quadro 2 - Perfil dos participantes

\begin{tabular}{|c|c|c|c|c|}
\hline \multirow{2}{*}{ Professores (P) } & Sexo & Curso & Tempo de docência superior & Experiência docente em cursos EAD \\
\hline P1 & P1 - M & Turismo & 5 anos & Não \\
\hline P2 & P2 - M & Turismo & 8 anos & Não \\
\hline P3 & P3 - M & Turismo & 20 anos & Sim ( 9 anos) \\
\hline P4 & P4 - F & Turismo & 26 anos & Não \\
\hline P5 & P5 - F & Turismo & 6 anos & \\
\hline
\end{tabular}

Fonte: Elaborado pelos autores, 2020.

Após as entrevistas, o material coletado foi transcrito e iniciou-se a categorização baseada metodologicamente nos pressupostos de análise categorial-temática de Bardin (2011). Para a definição das categorias de análise, utilizou-se a pesquisa de Estrada-Villa (2014) sobre fatores que favorecem a aprendizagem no ensino superior por meio de novas tecnologias. Entende-se que tal pesquisa é bastante apurada, dadas sua extensão de amostra e profundidade de discussão, e adequada para parametrizar a análise da situação de adaptação docente para novas tecnologias - problema em destaque na situação de adaptação para ensino remoto durante a pandemia.

\section{RESULTADOS E DISCUSSÃO}

Buscou-se construir e analisar os dados da pesquisa a partir das reflexões dos referenciais teórico-metodológicos. As categorias apresentadas por Estrada-Villa (2014) serviram de orientação para a construção das categorias do presente estudo. No entanto, destaca-se que, dada a singularidade do momento histórico vivenciado pelos participantes da pesquisa, no qual o distanciamento social lhes é imposto, algumas categorias emergem da análise dos depoimentos verbais, em consonância com os pressupostos de Bardin (2011).

Como resultados, identificou-se oito categorias: (1) atitude e interesse; características dos estudantes; (3) política da instituição de ensino superior; (4) ferramentas e recursos tecnológicos; (5) treinamento; (6) capacitação docente; (7) ambiente de trabalho e trabalho de reprodução social; (8) condições físicas e psicológicas. 
Referente à categoria atitude e interesse, considerou-se as falas que se constituíram de proposições nas quais o docente se coloca de forma propositiva ao uso de ferramentas e recursos tecnológicos para aulas remotas. O Quadro 3 apresenta os excertos das falas.

Quadro 3 - Categoria atitude e interesse

\section{ATITUDE E INTERESSE}

$P 1$ - "Eu sempre quis ter uma internet ativa com os alunos, com computador na mão para trabalhar em sala de aula e nunca foi possível fazer isso na IES2, pedi várias vezes e não consegui. Então, isso para mim tá sendo bom."

$P 2$ - "Tecnologicamente falando, eu aprendi muita coisa, mas, assim, coisa boa, talvez usar internet. Eu não tive facilidade no início. Hoje em dia, eu tô conseguindo dar jeito de fazer."

P3 - "Eu diria que, a cada semana, tem algo novo, alguma tecnologia bacana para utilizar."

$P 4$ - "a aula tem fluído bem melhor pela internet do que presencialmente, por quê? Porque os alunos pelo menos têm prestado mais atenção, então eles estão mais calados, não tem mais aquele zumzumzum na sala de aula."

P5 - “Aproximar a tecnologia da sala de aula [...] Interação [...] Usar o celular para fins pedagógicos. [...] Disponibilizar o material da disciplina pelo Ambiente virtual."

Fonte: Elaborado pelos autores, 2020.

Em relação à categoria características do estudante, percebeu-se que estas são consideradas muito importante no sucesso, ou não, da continuidade das atividades docentes dentro da modalidade ensino remoto, pois este último demanda certa autonomia e predisposição do estudante para utilizar as ferramentas e recursos e tecnológicos impostos pelas instituições privadas de ensino superior. Como resultado, apresenta-se no Quadro 4 tanto relatos positivos quanto negativos. Majoritariamente, esses docentes têm a percepção de conformismo por parte dos estudantes sobre o ensino remoto.

Quadro 4 - Categoria características do estudante

\section{CARACTERÍSTICAS DO ESTUDANTE}

$P 1$ - "Reclamam muito porque é uma plataforma que demanda muito uso de dados dos alunos. [...] se a opção da IES1 tivesse sido, por exemplo, WhatsApp, vários alunos poderiam acompanhar melhor as aulas."

$P 2$ - “Alguns são proativos, estão lá, e alguns não. A gente tem que estar junto. Eles falam pelo microfone, eles leem o texto, eles usam chat. Eles reclamam, mas eles aceitam. Mas, realmente, é um ambiente de conformação. A grande maioria se conformou."

$\boldsymbol{P} 3$ - "Estão curtindo essa interação, estão aprendendo a utilizar as ferramentas de maneira correta. Tudo que é diferente, no primeiro momento, incomoda. Os alunos fizeram abaixo-assinado, teve briga. [...] mas agora perguntam: professor, quando a gente voltar ao universo do normal, que nós tínhamos antes, a gente pode, eventualmente, fazer uma aula, um grupo de estudo, usar esse mecanismo ainda? É uma ferramenta que com certeza veio para ficar." 
$P 4$ - "Eles interagem muito, interrompem a aula, fazem perguntas por meio do chat, microfone e utilizam a mãozinha. Mas tem alunos que até hoje não conseguiram se apropriar da tecnologia, ou por uma dificuldade própria, ou seja, alunos com uma idade avançada que não tem a tecnologia introjetada neles."

P5 - "Eles estão se adaptando[...] Eles estão conformados (tem que ser, não tem para onde correr)."

Fonte: Elaborado pelos autores, 2020.

Já na categoria política da instituição de ensino superior, agrupou-se proposições dos participantes que apontavam ações institucionais referentes ao uso de tecnologias digitais nas aulas. Estrada-Villa (2014) já assinalava que "algumas IES estão mostrando sinais de estabelecer políticas para levar a tecnologia para a sala de aula, o que a torna um fator que favorece a inclusão da aprendizagem remota no ensino superior" (Estrada-Villa, 2014, p. 89). Devido ao contexto pandêmico, a presente pesquisa identificou que, no processo de decisão sobre o ensino remoto, os professores não foram consultados e não houve consulta coletiva sobre quais recursos tecnológicos (plataformas) seriam mais apropriados. O Quadro 5 apresenta falas referente à categoria supracitada.

Quadro 5 - Categoria Política da Instituição de Ensino Superior (IES) POLÍTICA DA INSTITUIÇÃO DE ENSINO SUPERIOR (IES)

$P 1$ - “A instituição escolheu usar o Microsoft teams para dar aula. Seria muito bom, se eles também oferecessem para os alunos as contas do Microsoft. Acaba que a gente ouve: "isso aqui é uma empresa!”

$\boldsymbol{P} 2$ - "No primeiro momento, ela (IES2) não tinha feito a pressão de que as aulas deveriam ser por videoconferência. Cada professor foi achando uma forma de continuar mantendo os alunos em algum processo de aprendizagem. Aí, cada professor foi usando uma ferramenta. Em depois de poucos dias, a chave virou, eles falaram: só pode ser Microsoft Teams e Skype! E aí sim, nós tivemos uma gestão um pouco mais diretiva em cima do uso do Teams, em uma janela de duas semanas mais ou menos."

$P 3$ - "Para gente, enquanto professor, tá sendo uma revolução. Quando a pandemia começou e foi estabelecida quarentena no Rio de Janeiro a gente estava indo para sexta aula presencial. Houve a comunicação institucional de que nós passaríamos trabalhar com a ferramenta do Teams."

$P 4$ - "Toda ferramenta de software me foi fornecida pela instituição, então eu não tive problemas. Temos suporte para o professor desde 7:50 até 10:20 da noite que é o último horário de aula."

$P 5$ - "No período de uma semana e meia, a instituição determinou que seria, a plataforma Teams, porque ela é uma plataforma que é da Microsoft [...] Eles (instituição) pediram para que a gente gravasse os encontros e também disponibilizasse para os alunos. Na instituição a gente não conseguia ter internet liberada para gente na sala de aula. Nesse novo processo é tudo impositivo, não existe uma consulta popular nem mesmo com os professores de dizer é Teams, é Zoom, é isso ou aquilo. Não é!"”

Fonte: Elaborado pelos autores, 2020.

No Quadro 6, apresenta-se falas referentes à categoria infraestrutura que está associada à dimensão de inclusão dos estudantes às tecnologias. Entende-se que a acessibilidade e infraestrutura dependem, por um lado, de recursos tecnológicos da universidade e, por outro 
lado, das condições de acesso dos estudantes a dispositivos ligados a tecnologias digitais e à internet.

\section{Quadro 6 - Categoria infraestrutura}

\begin{tabular}{|c|}
\hline INFRAESTRUTURA \\
\hline $\begin{array}{l}\text { P1 - “O que é muito ruim é que essa questão de ensino remoto não levou em consideração as desigualdades no } \\
\text { Brasil." }\end{array}$ \\
\hline $\begin{array}{l}P 2 \text { - "são alunos que às vezes o pai está desempregado, que ele tá desempregado, que não tem dinheiro, que a } \\
\text { internet é ruim, o computadorzinho é simples, tudo é muito simples." }\end{array}$ \\
\hline $\begin{array}{l}\text { P3 - "São em torno de } 40 \text { alunos, } 10 \% \text { dos alunos eles não têm computador em casa, eles não têm, no presente } \\
\text { mesmo. [...] Alunos que não têm boa internet e nem computador, acessam com o celular [...] O aluno que tinha } \\
\text { computador, mas não tinha câmera. O aluno que tinha um equipamento, mas era antigo, então teve que pedir } \\
\text { para o tio padrinho, madrinha, para o vizinho." }\end{array}$ \\
\hline $\begin{array}{l}\text { P4 - "Mas tem alunos que até hoje não conseguiram se apropriar da tecnologia ou por uma dificuldade própria, } \\
\text { por não ter uma boa internet, um bom computador ou celular bom, ou, por ter uma idade avançada que não } \\
\text { tem a tecnologia introjetada." }\end{array}$ \\
\hline $\begin{array}{l}P 5 \text { - “A realidade dos nossos alunos é que muitos não conseguem porque não tem o equipamento, não tem a } \\
\text { internet, não tem a privacidade em casa [...] às vezes, você tá dando aula e aí eles falam: "ah essa semana eu } \\
\text { consegui o computador emprestado!” }\end{array}$ \\
\hline
\end{tabular}

Fonte: Elaborado pelos autores, 2020.

Apresenta-se no Quadro 7 a categoria treinamento na qual as falas estão relacionadas ao treinamento para o uso das ferramentas digitais fornecidas pelas instituições de ensino superior a fim de dar continuidade às atividades de ensino.

Quadro 7 - Categoria treinamento

\section{TREINAMENTO}

P1- "Teve orientações em relação ao manuseio da plataforma. Teve gente da própria IES1 ensinando a usar, tinha um tutorial de como usar a plataforma."

$P 2$ - "Um passo a passo, mas não foi treinamento. Não teve ninguém fazendo um suporte no primeiro momento não."

$P 3$ - "Foi basicamente o professor assistir uma aula online de utilização na plataforma online, tivemos uma reunião geral, que foi um profissional do Microsoft que apresentou o Teams para todos os professores que tinham certa dificuldade, e depois, pontualmente, o moderador tentava ver com o professor qual era a dificuldade."

P4 - "Sim. Mas esses treinamentos não foram suficientes para gente aprender a mexer na ferramenta."

P5 - "Recebemos um tutorial de PowerPoint [...] Os coordenadores de curso fizeram encontro conosco também. [...] Temos um suporte contínuo (três ou quatro funcionários da TI que estão fazendo um plantão para dar este suporte)."

Fonte: Elaborado pelos autores, 2020. 
Do ensino presencial ao remoto: experiências dos docentes do bacharelado em Turismo durante a pandemia da Covid-

Devido ao contexto pandêmico, observou-se que o ensino-aprendizagem na modalidade ensino remoto não tem sido apoiado por estudos pedagógicos. Consequentemente, conforme apresentado no Quadro 8, identificou-se nos relatos certa insegurança dos professores quanto ao ensino, planejamento e avaliação das atividades pedagógicas, exceto para os docentes que já tinham experiência com a EAD. Esse fator corrobora com a discussão de que essa modalidade não tem planejamento prévio curricular e foi realizada de maneira abrupta.

Quadro 8 - Categoria capacitação docente

\section{CAPACITAÇÃO DOCENTE}

$\boldsymbol{P 1}$ - "Então, ainda bem que não teve nenhum treinamento que me prendesse mais. Não ter treinamento de vez em quando nos dá uma certa liberdade para a gente conseguir fazer algumas coisas boas, mas tem coisas muito ruins também."

$\boldsymbol{P} 2$ - "Nós não temos teorias pedagógicas e não temos experiências pedagógicas. Não temos estudos científicos na pedagogia. Não existe teoria para isso. Eu me sinto um cientista que vai para um laboratório ou para um experimento $100 \%$ indutivo sem base teórica nenhuma. Só que você nem vai tão vazio assim com para o indutivo, você tem uma base teórica, mas eu tô sem nenhuma."

P3 - "Como eu te falei da minha experiência com EAD, eu já tinha em casa material próprio para conseguir tocar a aula."

$P 4$ - "Como eu já sou professora da EAD e sou professora de outras instituições de pós-graduação também ead, eu particularmente não tive dificuldades de me adaptar. Eu acho que isso facilitou muito. A dificuldade que eu tive foi realmente de me familiarizar com Microsoft Teams porque eu nunca tinha utilizado."

$P 5$ - "Eu acho que é possível você fazer o aluno aprender. Só que o que eu acho injusto é a gente não se preocupar com quem são esses alunos, sabe!? E não se preocupar, inclusive, com a questão da metodologia."

Fonte: Elaborado pelos autores, 2020.

A categoria ambiente de trabalho e o trabalho de reprodução social emerge das análises dos dados e está ligada a todas as falas que remetem às questões ao ambiente laboral, as atividades cotidianas domésticas e as adaptações físicas para a realização das atividades remotas.

Quadro 9-Categoria ambiente de trabalho e o trabalho de reprodução social AMBIENTE DE TRABALHO E O TRABALHO DE REPRODUÇÃO SOCIAL

$P 1$ - “Eu já redecorei a casa toda, a minha casa não era assim. Eu fiz esse cenário todo aqui para dar as aulas. Botei umas plantinhas para fazer um negócio aqui, que também seja bom para os alunos quererem ficar assistindo, um cenário que fosse agradável para eles, eu tô ali, mas tô num cenariozinho que é legal e isso pode gerar algum tipo de entretenimento para eles. Mudei bastante coisa na casa e tal. Agora tem que cozinhar, lavar, limpar, organizar tudo."

$P 2$ - "Nesse ambiente de espaço de transição entre lazer e trabalho, você não sabe o que é o quê. A casa toda parece que é um lugar de trabalhar e que é um lugar de relaxar. Então, fica complicado. Eu dou aula na mesa da sala, em todas as gravações de aula tem a participação dela (Filha), ela fala: Oi gente!" 
P3 - "O que a gente precisou fazer foi dar uma arrumada no escritório que a gente usava eventualmente final de semana para rever o conteúdo de uma aula e fazer alguma coisa."

$P 4$ - "Eu tinha um computador adequado, então não tive problemas. Por sorte, eu tenho um ambiente na minha casa que é ultra apropriado. É silencioso e tudo mais, para eu poder dar aula. A iluminação, também tenho boa. [...] Quanto à conexão, ela foi suficiente."

P5 - "Eu não tenho como achar criatividade, se eu tô em 70 metros quadrados, em uma rotina acumulada, faz comida, faz atividade com criança, estuda, le alguma coisa, dá aula. Eu tenho sempre que dizer 'gente eu vou ter que desligar porque minha filha foi ao banheiro e eu tenho que ajudar."

Fonte: Elaborado pelos autores, 2020.

Apresenta-se no Quadro 10, a categoria condições físicas e psicológicas cujas narrativas dos entrevistados estão relacionadas a alguns impactos causados pelo isolamento social e pela adesão ao ensino remoto.

Quadro 10 - Categoria condições físicas e psicológicas CONDIÇÕES FÍSICAS E PSICOLÓGICAS

$P 1$ - "Vivia muito cansado fisicamente. Tomando Red Bull para dar aula. Agora mudou completamente. Eu tô dando aula com maior gás. Quando eu fico cansado é porque acabou a energia mesmo. [...] Eu me sinto muito vulnerável há muita maldade que acontece né?! se alguém pega uma parte desse vídeo e corta isso e tira de contexto e me expõe por exemplo, é uma coisa muito ruim né?! [...] O reitor tava matriculado em uma disciplina minha."

$P 2$ - "Eu antigamente tinha dias certos para estudar. Agora não tenho, é o tempo que sobra. Para mim, isso é péssimo porque isso impacta diretamente na aula. Não posso dar melhor atenção para minha filha e para minha esposa. Às vezes, o trabalho em casa, você vai acumulando coisa e vai deixando outras coisas para depois, e aí você perde."

$P 3$ - “Teve uma aluna, como eu te falei, não pela questão da tecnologia, mas pela questão social. A aluna falou 'gente tá acontecendo aqui um tiroteio e eu vou sair da aula para não atrapalhar mais'. Enquanto ela estava falando isso, a gente ficou ouvindo barulhos que eu não consigo nem descrever direito, eu não sei o que era, se era a granada, metralhadora, bomba, helicóptero, ou o que fosse. Mas, basicamente, eu não consegui naquele momento seguir com a aula, pedi para turma 10 minutos, e aí eu entrei em contato por WhatsApp com a aluna, para perguntar como ela estava, e ela tinha ido junto com os dois filhos deitar entre o fogão e a geladeira, para você ter noção. E a aula tá gravada, essa situação."

$P 4$ - "Os problemas se multiplicaram muito. Então eu trabalho 24 horas por dia. O volume de trabalho cresceu loucamente. Então, tem dias que se eu tivesse no presencial eu entraria, eu chegaria na IES2 às 3 horas da tarde. Mas agora dá 8 horas da manhã e eu já tô trabalhando, e não dou conta de tudo que eu tenho que resolver."

P5 - "Vira e Mexe você recebe uma mensagem de WhatsApp do aluno que você fala: 'gente o meu número realmente é público!' [...] Eu não sei até onde eu quero que as pessoas saibam, que tem um quadro aqui atrás. No começo isso me incomodava, só que paciência. [...] Você não tem mais um horário que você chega que você sai. Eu acho também que são tantos controles que a gente agora tem que se submeter para que a gente comprove a nossa produtividade. [...] Eu não sei se o cara tá jogado no chão porque tá tendo tiroteio: "professora, eu tenho computador, mas tá tendo tiroteio todo dia aqui”! Eu não sei, é desse nível a galera, que a gente ensina, são pessoas com muitas dificuldades, realmente com muitas dificuldades. Então, foi muito difícil, foi muito injusto."

Fonte: Elaborado pelos autores, 2020. 
A partir da sistematização das categorias percebeu-se que o ensino remoto não apenas expôs o problema da desigualdade ao acesso à tecnologia, mas descortinou, também, vários outros problemas que atingem tanto docentes quanto discentes, como: ambiência para estudos; saúde mental-psicológica; e falta de políticas públicas direcionadas à primeira infância para auxiliar mães e pais docentes (sobretudo, a desigualdade de gênero). Assim, talvez seja necessário (re)pensar se a sociedade acadêmica quer reproduzir a qualquer custo, mesmo em tempos de pandemia, a perspectiva individualista para lidar com essas questões.

Além disso, a partir da implantação do ensino remoto, observou-se com esta pesquisa: a necessidade de os docentes terem condições técnicas para realizar o trabalho remoto (falta de treinamento adequado sobre o uso das plataformas digitais). Foi identificado que não houve uma capacitação baseada em uma fundamentação didático-pedagógica para orientar esses docentes na condução do processo de ensino-aprendizagem. Considerando os apontamentos de Catramby e Costa (2005), tal ausência de capacitação docente poderá significar uma queda na qualidade de toda a formação desses discentes.

Todos os recentes acontecimentos decorrentes da pandemia da Covid-19 parecem revelar problemas relacionados à formação inicial e continuada dos professores referente ao uso de ferramentas e recursos tecnológicos, em particular as TICs no cotidiano escolar.

Observou-se que todos os participantes relataram casos de estudantes que ou não possuem equipamento adequado ou possuem o equipamento, mas são obrigados a compartilhálo com as outras pessoas da casa. Isso resulta em problemas de disponibilidade do dispositivo eletrônico nos horários das aulas virtuais dispostas pela universidade. Tais experiências corroboram os dados de acesso limitado da população a tecnologias digitais e revelam uma contradição na migração compulsória para o ensino remoto, mesmo em IES privadas (nas quais a maior parte do financiamento dos cursos é pelos próprios estudantes).

Pensando a dimensão institucional preconizada por Duvivier (2019), as IES são postas frente a um novo desafio: adequar a infraestrutura à nova realidade de descentralização espaciais das atividades pelo ensino remoto. As atividades que eram contratualmente e socialmente acordadas como presenciais foram migradas compulsoriamente para o ensino remoto por decisão exclusiva das IES, conforme apontado pelos entrevistados, sem diálogo ou participação dos docentes e discentes. Desponta, como necessidade para um processo de ensino remoto mais justo e adequado, a responsabilidade das IES em garantirem infraestrutura e condições materiais do ensino remoto para docentes e discentes (experiência que pode ser observada em algumas IES públicas). 
Concernente ao uso dos espaços domiciliares para atividades profissionais, especificamente as aulas remotas, há duas dimensões presentes nas percepções dos entrevistados. De um lado, os docentes relataram vantagens relacionadas fundamentalmente ao não deslocamento residência-trabalho, o que resultaria em princípio em otimização do tempo: “[...]quando termina não tenho que me preocupar com ônibus, já estou na minha casa, no conforto"(P3). Contudo, destacam que essa economia de tempo não se reverte em tempo qualificado no uso em outras atividades (lazer, descanso), ou seja, é convertido em mais trabalho: "[...] teoricamente tá todo mundo em casa, com conexão, na pandemia. Então, o volume de trabalho cresceu loucamente" (P4). Por outro lado, as rotinas foram profundamente afetadas: "a mudança é gigantesca, eu não consigo nem mensurar [...] Então, basicamente, as pessoas conhecem minha casa inteira. Não sei se eu queria que as pessoas vissem como é que a minha organização em casa, mas já superei, superado” (P5).

Também pôde-se observar que os docentes que já haviam realizado experiências de EAD, conforme apontado no Quadro 2, apresentaram algum nível de familiaridade com a ideia de ensino remoto. Entretanto, isso não representou a superação das dificuldades carregadas pelo ensino remoto compulsório. Isso porque, como apontaram Saraiva (1996) e Santos (2019), as educações à distância e online requerem, conceitualmente, um planejamento prévio acompanhado da preparação de materiais, currículos e métodos específicos para tais modalidades. Nesse sentido, ainda que os docentes mencionados tivessem mais preparo para adaptação de seu método pedagógico, os cursos não estavam preparados para atividades não presenciais - portanto, a experiência educativa empreendida não consegue atingir plenamente os requisitos das outras modalidades, ficando restritas ao ensino remoto.

Percebe-se que, diante da pandemia da Covid-19, os responsáveis educacionais das IES pesquisadas buscaram manter as aulas a qualquer custo. Contudo, deparam-se com professores sem formação em tecnologias; parte dos estudantes sem conexão à internet, ou mesmo, sem acesso à internet; e sem o conhecimento prévio dos recursos digitais adotados para dar continuidade ao ano letivo. Esse conjunto de fatores dificultou o trabalho desses docentes, o que pode também prejudicar a formação dos estudantes.

Tal perspectiva representa um risco a todo o desenvolvimento do turismo. Conforme apontado na seção 3, as qualificações necessárias aos profissionais do setor, apontadas por Santos (2007), tornaram-se ainda mais fundamentais frente ao cenário de mudanças radicais gerado pela pandemia. Entretanto, se a atuação docente está prejudicada pela ausência de capacitação em tecnologias, é provável uma queda na qualidade da formação desses profissionais. A pandemia traz, assim, uma contradição: por um lado, exige uma formação ainda 
mais complexa dos estudantes; por outro, prejudica o trabalho docente e a qualidade da formação. Portanto, revela-se fundamental uma atuação das IES mais comprometida com a formação em turismo do que com a manutenção dos lucros das próprias instituições.

\section{CONSIDERAÇÕES FINAIS}

Por ainda se desenhar um quadro incerto em relação ao retorno das aulas presenciais nos cursos de graduação em turismo no Brasil, esta pesquisa teve como objetivo investigar as experiências dos docentes de cursos presenciais de graduação em turismo devido à implementação do ensino remoto. Nesse contexto, a adoção de 'alternativas educacionais' de forma remota tem sido a solução para dar continuidade às práticas educacionais. De certa forma, no que tange às instituições privadas de ensino superior, como há um contrato comercial entre estudante e instituição, estas têm como obrigação oferecer o serviço educacional e o estudante o direito de acesso.

Como visto, há diferenças entre EAD, educação online e ensino remoto. Lecionar por meio de uma plataforma virtual não significa EAD e nem educação online. Por isso, as instituições de ensino precisam ter o cuidado e a honestidade em usar o termo adequado ao que se está oferecendo como ensino durante o período de distanciamento social.

Destaca-se, também, os problemas que os docentes enfrentam em relação ao treinamento educacional (ou a falta deste) para o uso das plataformas digitais. Outro fator que foi ressaltado pelos participantes diz respeito às condições psicológicas desses profissionais diante do isolamento social devido ao crescente número de casos e de óbitos, inclusive nas famílias dos estudantes e colegas de trabalho. Os impactos que afetam física e psicologicamente os participantes desse contexto são reforçados pelas condições de moradia (espaços compartilhados) e das tarefas domésticas que historicamente recaem com maior peso sobre as mulheres - potencializado no grupo de mulheres pretas e pobres. A presente pesquisa evidencia uma questão de gênero, que pode intensificar ainda mais desigualdades no atual cenário pandêmico.

Apreende-se que as experiências com o ensino remoto - destacados os recortes de IES privadas e do período inicial do isolamento social obrigatório - investigadas na presente pesquisa revelaram-se de precarização do trabalho docente. As múltiplas dificuldades enfrentadas tanto por docentes quanto por discentes retroalimentam-se em um processo que tende à queda da qualidade do processo educativo e, consequentemente, da formação profissional e da qualidade geral dos serviços prestados no setor do turismo por turismólogos. 
De fato, há muitas questões envolvidas nesse processo de obrigatoriedade do ensino remoto, que não surgem com a pandemia, mas aumenta significativamente o processo de precarização do trabalho docente e a possibilidade de demissões massivas de profissionais da educação. Além disso, a pandemia pode estar sendo um laboratório para acelerar o desmonte do ensino presencial, visando fornecer oportunidades para o empresariado educacional lucrar com fundos de investimento em educação privada superior a distância. Pondera-se, ademais, que não é possível pensar políticas de educação destituídas de políticas de inclusão digital.

\section{REFERÊNCIAS}

Apple, M. (1986). O Computador na Educação: parte da solução ou parte do problema? Revista Educação e Sociedade, (23), 25-49, São Paulo: Cortez Editora.

Ansarah, M. (1995). Educação e formação do bacharel em Turismo. Revista turismo em análise, 6(1), 44-64.

Baranauskas, M., \& Valente, J. (2013). Editorial. Tecnologias, Sociedade e Conhecimento, 1(1), 1-5. Recuperado de http://www.nied.unicamp.br/ojs/index.php/tsc/issue/current

Bardin, L. (2011). Análise de conteúdo. São Paulo: Edições 70.

Brasil. (2020a). Ministério da Saúde. Recuperado de

https://www.saude.gov.br/noticias/agencia-saude/46435-brasil-confirma-primeiro-caso-denovo-coronavirus

Brasil. (2020b). Ministério da Educação. Parecer CFE n. ${ }^{\circ}$ 35/1971, de 28 de janeiro de 1971. Ministério da Educação. Acedido em 01 de maio de 2020. Recuperado de http://www.mec.gov.br

Brasil. (2020c). Ministério da Educação. Cadastro Nacional de Cursos e Instituições de Educação Superior Cadastro e-MEC. Recuperado de https://emec.mec.gov.br/

Catramby, T., \& Costa, S. (2005). Estudo de caso sobre a capacitação docente na área de turismo no estado do Rio de Janeiro. Caderno Virtual de Turismo, 5(2), 11-28.

Cochran, W. (1965). Técnicas de Amostragem. Rio de Janeiro: Editora Fundo de Cultura S. A.

Costa, S., Duqueviz, B., \& Pedroza, R. (2015). Tecnologias Digitais como instrumentos mediadores da aprendizagem dos nativos digitais. Psicologia Escolar e Educacional, 19(3), 603-610.

Duvivier, R. (2019). How to 'future-proof' the use of space in universities by integrating new digital technologies. Perspectives: Policy and Practice in Higher Education, 23(1), 18-23,

Empresa Brasil de Comunicação - EBC. (2020). Agência Brasil de Comunicação. Estado do Rio de Janeiro confirma primeiro caso de coronavírus. Recuperado de 
https://agenciabrasil.ebc.com.br/saude/noticia/2020-03/estado-do-rio-de-janeiro-confirmaprimeiro-caso-de-coronavirus-0

Ellis, R., \& Goodyear, P. (2016). Models of learning space: integrating research on space, place and learning in higher education. Review of Education, 4 (2), 149-19.

Estrada-Villa, E. (2014). Factores que contribuyen y dificultan el desarrollo de la enseñanza aprendizaje mediada por dispositivos móviles en instituciones de educación superior en Colombia. Tesis de Maestría. Universidad de La Sabana, Chía, Colombia. Recuperado de https://intellectum.unisabana.edu.co/bitstream/handle/10818/11596/Erika\%20 Juliana\%20Estrada\%20Villa\%20\%28tesis\%29.pdf?sequence=1\&isAllowed=y

Gil, A. (2002). Como elaborar projetos de pesquisa. (4a ed.). São Paulo: Atlas.

Imprensa Oficial do Estado do Rio de Janeiro - IOERJ. (2020). Imprensa Oficial do Estado do Rio de Janeiro. Recuperado de

http://www.ioerj.com.br/portal/modules/conteudoonline/mostra_edicao.php?session=VGxWV mQwOVZTa1ZOTUZWMFRWVIJNRTU1TURCT1JHaEhUR1JyTIU0d1VYUk9WRUpIV WtSamVrOUViRVZPZW1zdw==\&p=Mg==\&tb=REVDUkVUTyA0Njk3MyYjMDEzOw==

Kenski, V. (1998). Novas Tecnologias: o redimensionamento do espaço e do tempo e os impactos no trabalho docente. Revista Brasileira de Educação, 8, 58-71.

Kenski, V. (2012). Educação e tecnologias: o novo ritmo da informação. (8a ed.). Campinas: Papirus.

Li, R., Pei, S., Chein, B., Song, Y., Zhang, T., Yang, W., \& Shaman, J. (2020). Substantial undocumented infection facilitates the rapid dissemination of novel coronavirus (SARS-CoV2). Science, 368(6490), 489-493.

Moore, M., \& Kearsley, G. (2008). Educação a distância: uma visão integrada. São Paulo: Cengage Learning.

Oliveira, C., Cheretti, E. A., Nascimbem, N. M. S., Sidericoudes, O., Faça, V. R., \& Ortelli, V. R. (1993). Expectativas e reflexões sobre o uso do computador como recurso pedagógico. Valente, J. A. (Org.). Computadores e Conhecimento: repensando a Educação, 386-394. Campinas: UNICAMP.

Organização das Nações Unidas para Educação, Ciência e Cultura - UNESCO. (2012). Mobile learning and policies. Key issues to consider. Paris. Recuperado de http://unesdoc.unesco.org/images/0021/002176/217638E.pdf

Organização Mundial de Saúde - OMS (2020). World Health Organization. Recuperado de https://www.who.int/dg/speeches/detail/who-director-general-s-opening-remarks-at-themedia-briefing-on-covid-19---11-march-2020

Preti, O. (2005). Educação a distância: sobre discursos e práticas. Brasília: Liber Livro.

Qun, L. et al. (2020). Early transmission dynamics in Wuhan, China, of novel coronavirusinfected pneumonia. The New England Journal of Medicine, 382, 1119-1207.

Rio de Janeiro (Estado) (2020). Decreto Estadual no 47.068, de 11 de maio de 2020. Dispõe sobre as medidas de enfrentamento da propagação do novo Coronavírus e dá outras 
providências. Rio de Janeiro/RJ. Recuperado de

https://pge.rj.gov.br/comum/code/MostrarArquivo.php?C=MTA4MjU\%2C

Santos, M. (2007). Prática docente na formação do turismólogo. Revista Brasileira de Pesquisa em Turismo, 1(1), 84-109.

Santos, E. (2019). Pesquisa-formação na cibercultura. Teresina: EDUFPI.

Saraiva, T. (1996). Educação a distância no Brasil: Lições da história. Em Aberto, Brasília, 16(70), 17-27.

Silveira, C., Medaglia, J., \& Gândara, J. (2012). Quatro décadas de ensino superior de turismo no Brasil: dificuldades na formação e consolidação do mercado de trabalho e a ascensão de uma área de estudo com efeito colateral. Revista Turismo Visão e Ação, 14 (1).

Tosta, S., \& Oliveira, M. (2000). O Computador não é uma lousa: as tecnologias de comunicação e informação e a prática docente. Anais $24^{a}$ Reunião Anual ANPED. Recuperado de www.anped.org.br

Trigo, L. (1998). A sociedade pós-industrial e o profissional em turismo. (6a ed.). Campinas: Papirus.

Trigo, L. (2000). A importância da educação para o turismo. In: Lage, B., \& Milone, P. (Orgs.). Turismo: teoria e prática. São Paulo: Atlas.

SILVA, M. H., HASTENREITER, R. S. C., SANTOS, M. L., \& SILVA, I. C. M. (2021). Do ensino presencial ao remoto: experiências dos docentes do bacharelado em Turismo durante a pandemia da Covid-19. Revista de Turismo Contemporâneo, 9(2), 172-194. https://doi.org/10.21680/2357-8211.2021v9n2ID23516 